Article

\title{
Improving Self-Efficacy Towards Inclusion in In-Service Physical Education Teachers: A Comparison between Insular and Peninsular Regions in Spain
}

\author{
Raul Reina ${ }^{1}\left[\right.$, Alicia Santana ${ }^{2}$, Rayco Montesdeoca ${ }^{2}$ and Alba Roldan ${ }^{1, * *(])}$ \\ 1 Sport Research Centre, Department of Sport Sciences, Miguel Hernández University, 03202 Elche, Spain; \\ rreina@goumh.es \\ 2 Department of Physical Education, University of Las Palmas de Gran Canaria, 35017 Las Palmas de Gran \\ Canaria, Spain; alicia.santana@ulpgc.es (A.S.); rayco.montesdeoca@ulpgc.es (R.M.) \\ * Correspondence: aroldan@umh.es; Tel.: +34-96-522-2452
}

Received: 30 September 2019; Accepted: 18 October 2019; Published: 20 October 2019

check for updates

\begin{abstract}
Physical education teachers play a significant role in educating students with special education needs, but they often feel frustrated and unprepared to achieve a successful inclusion process. The lack of inadequate training has proven to have an unfavorable effect on educators' perceived competence, confidence, and attitudes when working in inclusive settings with children with disabilities. This study evaluates the effect of a training program implemented with in-service physical educators from two different regions in Spain, insular and peninsular, in order to improve their self-efficacy in including students with disabilities in physical education. A pre- vs. post-test intervention was conducted with two groups of 142 in-service physical educators with similar age and teaching experience. The intervention improved their perceived self-efficacy in including students with physical, visual, and intellectual disabilities in physical education $(p<0.01$, effect sizes $=$ large). The physical educators teaching in the insular region improved their self-efficacy to a higher extent. This study demonstrates the invariant effect of the training program in both regions, but the self-efficacy scores of the physical educators might be constrained by the contents regarding inclusion in their pre-service training, the education policies of the region where the teaching takes place or the geographical characteristics of their workplace.
\end{abstract}

Keywords: para-sport; inclusion; self-competency

\section{Introduction}

Students with disabilities are increasingly included in mainstream education systems. The access of these students to the practice of physical education (PE) is a fundamental right for all of them, as stated by the United Nations [1]. However, physical education teachers (PET) are often frustrated with their inability to accommodate inclusion in mixed-ability PE classrooms for reasons related to students' safety or the difficulty in designing tasks that do not negatively impact the type and severity of the disability [2]. Many PE teachers feel that their education system did not sufficiently prepare them to undertake this role [3]. This seems to be a common situation in many countries, as it was reported in the latest Teaching and Learning International Survey (TALYS) that 22\% of teachers across the Organization for Economic Cooperation and Development (OECD) asked for more training in teaching students with special needs [4]. In 2015, the United Nations established Sustainable Development Goal Four (SDG-4), which focuses on quality education, aiming to ensure that qualified, professionally trained, motivated, and well-supported teachers are available to all students [5] and highlighting the role that teachers play in the complex education process. However, when talking 
about students with disabilities, studies in inclusive education have demonstrated that PETs present negative attitudes towards their inclusion, driven by their poor self-efficacy (SE) in meeting students' needs [6-8]. It seems clear that investing in teacher training is crucial for the effective delivery of the UNESCO Education Agenda, as teachers who present adequate subject and pedagogic content knowledge and are well-trained in the necessary skills can make a huge difference in educating students, especially those with special needs [9]. Education for sustainable development has encompassed a wide range of objectives to ensure that teachers help students understand the rapidly changing world in which they live, as well as the need to participate in that world. Because of this, investigating teacher-training programs is necessary for the understanding of evidence-based inclusive practices and to address common concerns and misconceptions about inclusion. When this happens, PETs apply strategies in practice, design learning experiences for students of all abilities, and support participation by students with disabilities, resulting in increased student learning [10]. However, to the best of the authors' knowledge, studies that present evidence-based strategies based on action-oriented pedagogy to promote education for sustainability in PE are scarce.

To improve professional standards in inclusive physical education (IPE), it is necessary that education/training curricula present those contents as a contribution to achieving proper PET training [11,12]. Education is very dynamic, and there is no universal design for educational programs, which are heavily influenced by national education curricula and, thus, differ across countries. Education policies can also be influenced by the geographical and economic dimensions of a country and by the spatial distribution of the population [13]. Therefore, it is plausible for education curricula to differ within a nation-state or region [14]. A clear case occurs in Spain, a country that has 17 autonomous regions, two of them belonging to insular areas (i.e., the Balearic Islands and the Canary Islands). Although since 2013, there has been a national education law with clear inclusion policies [15], each Spanish region has the authority to design its own educational curricula, including policies about inclusive education. It is for this reason that such inclusive policies may vary between Spanish regions. Educational differences between peninsular and insular areas have already been reported in several studies $[13,16]$, but, to the authors' best knowledge, there is no previous research on this topic applied to a PE context. For example, the two regions examined in this study have disparate university programs for pre-service PET, including content regarding the inclusion of students with special education needs in PE.

Considering the aforementioned, the aim of this study was to deliver an in-service PET training course on inclusive physical education, comparing the outcomes of PET from insular and peninsular regions. The hypotheses of this study were i) good PET training can significantly improve PET self-efficacy towards students with disabilities, and ii) the self-efficacy improvement ratio is constrained by the region where the teaching takes place.

\section{Materials and Methods}

\subsection{Participants}

An original group of 416 in-service PETs was recruited for this study from two regions in Spain: 240 from the Valencian Community (a peninsular region) and 176 from the Canary Islands (an insular region). With the aim of comparing the intervention program between regions, we only include in the study those in-service PETs that met the following inclusion criteria: i) having a university diploma to teach at primary or secondary school levels, ii) a minimum of two years of teaching experience in $\mathrm{PE}$, iii) participation in all the sessions $(\mathrm{n}=6)$ of the intervention program, and iv) responding to all the items on the self-efficacy questionnaire. After removing those that did not meet the criteria from the dataset, the final selection was done using a random number generator (StatTrek.com., 2019) to obtain a sample with a balanced N, age, and training experience in PE scores (Table 1). Therefore, $68.3 \%$ of the original sample was used for this study. All participants gave their informed consent for inclusion before they participated in the study. The intervention was conducted in accordance with the Declaration of Helsinki and the protocol was approved by the Ethics Committee of the principal investigator's university (DPS.RRV01.15). 
Table 1. Sociodemographic characteristics of the participants.

\begin{tabular}{cccc}
\hline Region/Gender & $\mathbf{N}$ & Age $(\mathbf{y r})$ & Teaching Experience $(\mathbf{y r})$ \\
\hline Peninsular & & & \\
Male & 74 & $37.6 \pm 7.2$ & $10.8 \pm 7.1$ \\
Female & 65 & $38.7 \pm 8.0$ & $13.0 \pm 8.0$ \\
Overall & 142 & $38.0 \pm 7.5$ & $11.8 \pm 7.6$ \\
Insular & & & \\
Male & 69 & $38.5 \pm 8.5$ & $9.6 \pm 8.2$ \\
Female & 73 & $41.3 \pm 7.6$ & $11.6 \pm 8.5$ \\
Overall & 142 & $40.0 \pm 8.2$ & $10.7 \pm 8.4$ \\
\hline
\end{tabular}

\subsection{Measures}

The Self-Efficacy Scale for Physical Education Teacher Education Majors towards Children with Disabilities (SE-PETE-D) was used to evaluate changes in SE. The questionnaire was created and validated by Block et al. [17] in English and adapted to the Spanish context by Reina, Hemmelmayr, and Sierra-Marroquín [18] (Escala de Autoeficacia en Profesores de Educación Física hacia Alumnos con Discapacidad (EA-PEF-AD)). The questionnaire begins with a general introduction to Bandura's SE theory and general guidance for using the rating scale to answer the questions. Then three vignettes are presented, describing a child with an intellectual disability, a physical disability, and a visual impairment respectively, followed by three sets of 10-12 questions relating to fitness testing, teaching sport skills, and organizing the actual playing of a sport. The questions measure how competent the PET feels in each category. The competency scale (a Likert scale) for each question ranges from 1 (no confidence) to 5 (complete confidence). Higher scores on these three sub-scales mean higher perceived competence to accommodate or include a student with special education needs in PE.

The measurements were administered anonymously to the intervention groups as a pre-test before the commencement of the training program, and the post-test was administered after the last session (session 6). To maintain anonymity, pre-, and post-test scales were matched using a free-choice code (e.g., picture, last digits of telephone number or ID, etc.).

\subsection{Procedures}

The course's dissemination was done in cooperation with the two regional governments where the training programs took place, specifically with their offices for education affairs. All of the teachers participated in the courses voluntarily, and the completion of the courses was valuable for their lifelong training. In the peninsular region, courses were conducted in different places in the three provinces of the Valencian Community (Alicante, Castellón, and Valencia), while courses in the insular regions were conducted on three islands (Fuerteventura, Gran Canaria, and Tenerife).

The intervention program (Incluye-T) contains the structure and teaching skills recently described by Reina et al. [8]. This training program aims to improve the SE of the participating PETs to successfully include students with a disability in PE via the development of the necessary attitude, knowledge, and skills. The program consisted of six sessions, each $3 \mathrm{~h}$ in duration, conducted during three consecutive weeks, two days per week. All the courses were conducted in the evening, that is, after working hours at the regular schools. The training sessions were structured as follows: 1) pre-test, theoretical session about the principles and benefits of inclusion and an awareness lesson (practical activity and debate) about different impairments; 2) IPE for students with visual and hearing impairments (information on characteristics and teaching strategies, simulation, practical activity, and debate); 3) IPE for students with physical impairments (information on characteristics and teaching strategies, simulation, practical activity, and debate) and applied wheelchair skills (e.g., positioning, propulsion and safety straps, fifth wheel, etc.), 4) IPE for students with intellectual impairments (information on characteristics and teaching strategies, simulation, practical activity, and debate); 5) para-sport (Boccia and/or sitting volleyball), and 6) Paralympic sport session with a para-athlete (i.e., direct contact), debate and post-test. 
All the principal elements of the training program, e.g., duration, number, and distribution of sessions, administration of pre- and post-tests, instructors, content, and time of contact with a para-athlete, were kept constant. Each of the program's offerings included 12-24 in-service PETs and was conducted between February 2016 and May 2019. To guarantee the consistency of the interventions across regions, the principal investigator of the project traveled to the Canary Islands for a pre-intervention training of the instructors who taught the courses in that region.

\subsection{Data Analyses}

All of the SE scores are presented as mean (M) and standard deviation (SD). Data were screened for normality of distribution and homogeneity of variance using the Kolmogorov-Smirnov test and Levene's test, respectively, to determine the appropriateness of using parametric techniques for data analysis. EA-PEF-AD reliability was assessed by Cronbach's alpha calculation, considering scores over 0.70 acceptable [19]. In order to determine the internal consistency of the scale to evaluate SE, the relationships among EA-PEF-AD sub-scales were assessed using Pearson's product-moment correlations $(r)$. The following scale of magnitudes was used to evaluate correlation coefficients: $<0.1$, trivial; 0.1-0.3, small; $<0.3-0.5$, moderate; $<0.5-0.7$, large; $<0.7-0.9$, very large; and $<0.9-1.0$, almost perfect [20].

The change in the level of SE was analyzed using a mixed $2 \times 2$ ANOVA, using pre-post-intervention scores as the within-group factor and the teaching region (i.e., peninsular vs. insular) as the between-group factor. Practical significance was calculated by partial eta-square $\left(\eta \mathrm{p}^{2}\right)$ as a measure of effect size for mean differences with the following interpretation: $>0.26$, large; between 0.26 and 0.02, moderate; and $<0.02$, small [21]. In addition, pairwise effect sizes $(90 \%$ of confidence interval) for within-group comparisons are expressed in Cohen's $d$ units and interpreted as follows: trivial $(<0.19)$, small $(0.20-0.49)$, moderate $(0.50-0.79)$, and large $(>0.80)$ [22]. All calculations were carried out using the Statistical Package for Social Sciences (version 25.0 for Windows; SPSS Inc, Chicago, IL, USA) and Microsoft Excel (Microsoft, Seattle, WA, USA). The level of statistical significance to reject null hypotheses was set at $p<0.05$.

\section{Results}

\subsection{Scale Reliability and Internal Consistency}

Table 2 shows the reliability scores for the EA-PEF-AD, considering the moment of the data collection (i.e., pre vs. post-intervention) and the between-group (i.e., peninsular vs. insular) factors. All the measurements exhibited excellent reliability scores $(0.91<\alpha<0.96)$. The scale also shows good internal consistency, with large to very high correlations $(0.62<r<0.80 ; p<0.01)$.

Table 2. Reliability and internal consistency of the self-efficacy scale.

\begin{tabular}{cccccccc}
\hline \multirow{2}{*}{ Self-Efficacy Subscale } & \multicolumn{3}{c}{ Pre-Intervention } & \multicolumn{3}{c}{ Post-Intervention } \\
\cline { 2 - 7 } & $\alpha$ & Cor. Ps & Cor. Vs & $\alpha$ & Cor. Ps & Cor. Vs \\
\hline Intellectual (Is) & & & & & & \\
$\quad$ Peninsular & 0.93 & $0.70^{* *}$ & $0.62^{* *}$ & 0.93 & $0.75^{* *}$ & $0.65^{* *}$ \\
$\quad$ Insular & 0.92 & $0.79^{* *}$ & $0.68^{* *}$ & 0.91 & & \\
Physical (Ps) & & & & & & \\
$\quad$ Peninsular & 0.96 & - & $0.65^{* *}$ & 0.94 & - & $0.77^{* *}$ \\
$\quad$ Insular & 0.94 & - & $0.74^{* *}$ & 0.94 & - & $0.80^{* *}$ \\
$\quad$ Visual (Vs) & & & & & & \\
Peninsular & 0.95 & - & - & 0.95 & - & - \\
$\quad$ Insular & 0.95 & - & - & 0.92 & - & - \\
\hline
\end{tabular}

$\alpha$ : Cronbach's alpha, Cor.: Pearson's correlation, Is: intellectual subscale, Ps: physical subscale, Vs: visual subscale, ** $p<0.01$. 


\subsection{Between-Groups Comparisons and Interaction Effects}

Figure 1 shows the pre- vs. post-intervention comparisons considering the region or the PET's workplace. The $2 \times 2$ ANOVA shows positive and large effects of the intervention for all the EA-PEF-AD subscales: intellectual $[\mathrm{F}(1,282)]=698.98 ; p<0.01 ; \eta \mathrm{p}^{2}=0.71$, large $]$, physical $[\mathrm{F}(1,282)]=951.92$; $p<0.01 ; \eta \mathrm{p}^{2}=0.77$, large $]$ and visual $[\mathrm{F}(1,282)]=1004.05 ; p<0.01 ; \eta \mathrm{p}^{2}=0.78$, large $]$. In addition, this analysis demonstrates interaction effects between the intervention and the region factors for all the subscales: intellectual $[\mathrm{F}(1,282)]=31.44 ; p<0.01 ; \eta \mathrm{p}^{2}=0.10$, moderate], physical intellectual $[\mathrm{F}(1,282)]=10.71 ; p<0.01 ; \eta \mathrm{p}^{2}=0.04$, moderate $]$, and visual $[\mathrm{F}(1,282)]=4.20 ; p=0.04 ; \eta \mathrm{p}^{2}=0.02$, moderate]. Overall, it can be observed that the group from the insular region has had a greater improvement in their SE scores, that is, from a mean score of 2.77 to a final score of 4.23 (>1.46 points), while the PETs from the peninsular region improved from an overall score of 3.00 to a final score of 4.10 (>1.10 points). Analyzing these improvements per subscale $(p<0.01, d=$ large), the insular group had higher increases in their SE scores in all the measurements (insular vs. peninsular): intellectual $(d=-1.90$ vs. -1.19$)$, physical $(d=-1.95$ vs. -1.49$)$ and visual $(d=-1.87$ vs. -1.72$)$.

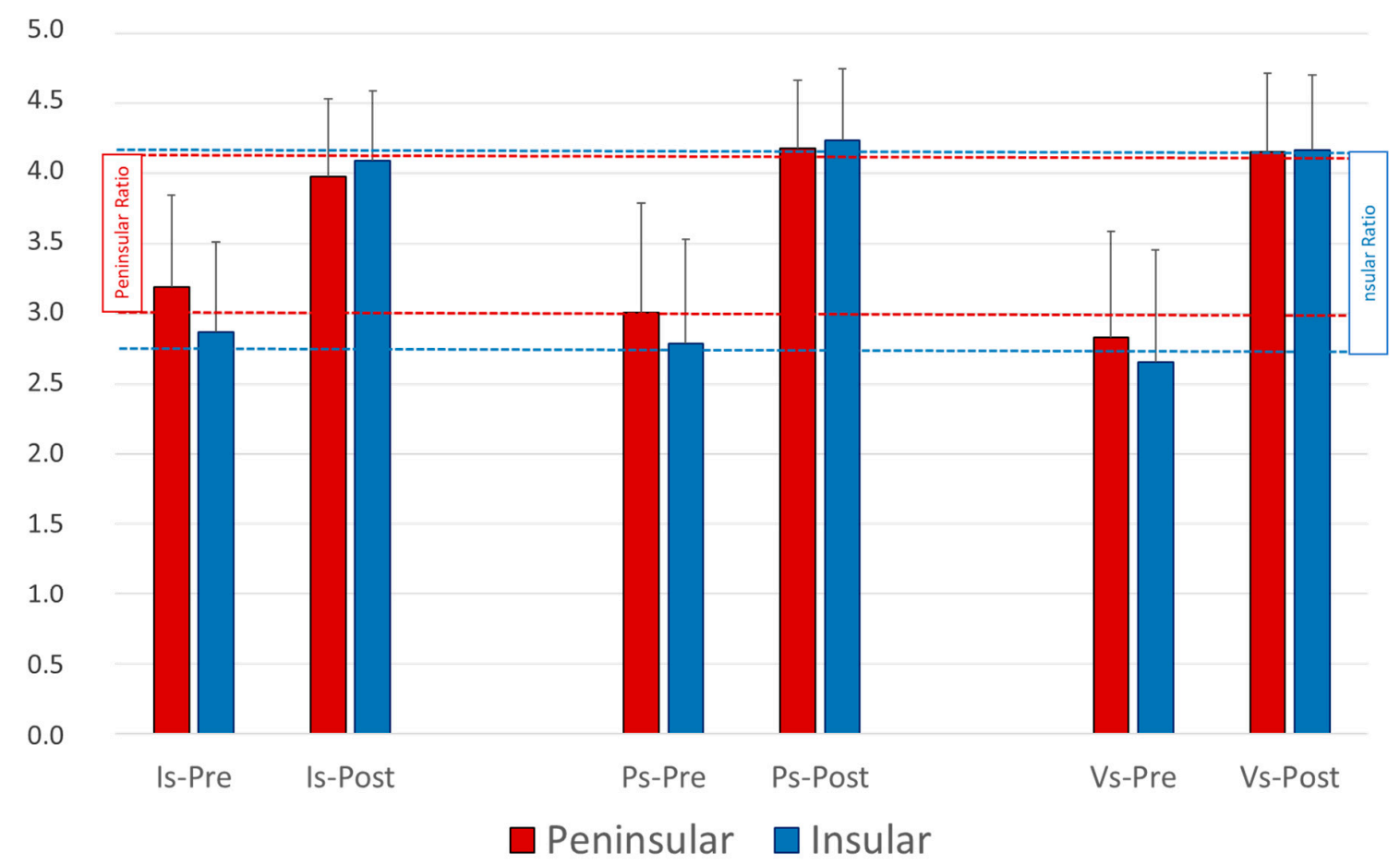

Figure 1. Pre- vs. post-intervention results by region. The overall ratio of improvement is presented for each region. Is: intellectual subscale, Ps: physical subscale, Vs: visual subscale.

\section{Discussion}

The aim of this study was to compare the implementation of a teacher education program in two different geographical regions in Spain, one peninsular (i.e., Valencian Community) and one insular (i.e., Canary Islands), to improve in-service PET self-efficacy in including students with intellectual, physical and visual disabilities.

Results showed that the training program achieved positive improvements in PET's self-efficacy in both regions. The methodology used in the courses is a key factor to consider. Both courses were structured according to four teaching strategies that international literature has shown effective in improving both attitudes towards and knowledge of the inclusion of people with a disability [23]. First, a simulation was used in all the training sessions with the PETs, and they had to experience a disability during all the practical tasks, whether physical, sensory, or intellectual, depending on the content of the session [8]. The understanding of the limitations experienced by students with disabilities 
in PE sessions makes it easier for PETs to be aware of difficult situations and to better cope with these students [24,25]. Second, we provided the Incluye-T guide (available at Reina et al. [8]), an ad hoc guide that includes information and multimedia resources, such as inclusion and instructional strategies, adaptation of activities considering several types of impairment, practical lessons, and infographics for all summer and winter Paralympic sports. For example, the infographic cards present a brief explanation of each para-sport, including information on the rules and the specific equipment needed for its practice, basic information about the classification system used in the para-sport, a brief biography of a local or national para-athlete and a QR code that directs the reader to a video that further explains each para-sport (e.g., Paralympics A-Z by the International Paralympic Committee). These types of materials encouraged interaction on the part of the PETs, and they could also be used in their regular PE classes as a training resource for their professional development [26]. The original version of the Incluye-T guide received minor adjustments for its implementation in the insular region, and it is available as Supplementary Material for this publication (appendix A). Third, contact with a para-athlete is a teaching strategy based on contact theory [27], aiming to dismiss prejudices and improve relationships between members of the majority and minority groups, such as the inclusion of a student with a disability in a regular PE class. The education program is designed in such a way that, in the last session of the course, teachers could work with a para-athlete to achieve the four components of the contact theory: personal interactions, equal status, social acceptance, and cooperation [28]. The fourth strategy was curriculum intervention: The content of courses was similar in both regions and was selected on the basis of inclusion in the national education law and previous evidence for the virtues of using Paralympic sports in PE [29]. The combination of these four methodological strategies, as well as the content covering the three largest disability groups (i.e., physical, sensory, and intellectual), have made the training program very effective in improving the self-efficacy of the participating teachers, as results from both areas showed. Therefore, the first hypothesis for this study would be accepted.

Although PETs in both programs achieved the same levels of self-efficacy improvement, insular PETs started with a lower baseline level of self-efficacy, showing a higher improvement ratio, confirming the second hypothesis for this study. This disparity will be discussed considering three factors: i) the university curricula regarding inclusion, to prepare physical educators for teaching at primary or secondary schools; ii) the regional education curriculums established by each regional government and iii) some geopolitical considerations with regards to the two regions of this study.

First, if we compare undergraduate teachers' preparation curricula for primary and secondary school levels in the Valencian Community (peninsular area) and the Canary Islands (insular area), differences in IPE training are observed. In the Valencian Community, there are four universities (Alicante, Catholic of Valencia, Miguel Hernández, and Valencia) offering official studies in physical education and sport sciences to enable access for teaching at the secondary school level, and five more universities in the region (Alicante, Cardenal Herrera, Catholic of Valencia, Valencia, and Jaume I Castellón) offer official studies in education that enable teaching at primary school. In the insular region, these studies are actually offered in one (Las Palmas de Gran Canaria) and two (Las Palmas de Gran Canaria and La Laguna) universities, respectively. Together with the number of universities offering official studies for pre-service PETs, a key factor here was the adaptation of study plans to the European credit system (ECTS) since 2010. Regarding the physical activity and sport sciences degree, previously implemented by the ECTS, all the Valencian universities included a 4.5-credit (i.e., 45 teaching hours) subject entitled Physical Activity for Special Populations in their study plans, while in the insular regions, it was a part of a broader subject ( 9 credits) including content about physical conditioning, ergonomy, and physical activity for health. Therefore, the current in-service PETs who were trained with these study plans may not receive proper training in inclusion, supporting the effectiveness of our program and the higher improvement ratio for those in the insular region. In addition, the recommendations for developing new ECTS study plans in physical activity and sports sciences in Spain [30] include the descriptor of Adapted Physical Activity and Adapted Sports as part 
of the Physical Activity and Health curriculum. This general recommendation has been translated into a disparity with regard to our study subject, from 6 to 7.5 ECTS credits and with an educative (Alicante and Las Palmas de Gran Canaria), sports and leisure (Catholic of Valencia), health (Valencia), or mixed (Miguel Hernández) approach. Although new generations of PETs have received some specific training about inclusion in a PE context, the age and teaching experience of the physical educators involved in this study would explain their lack of preparation on this topic, considering the approach of the contents of the pre-ECTS study plans. This fact could be also applied to those trained for teaching at primary schools (i.e., university degree in education). In Spain, before the ECTS implementation, there was generally an optional 4.5-credit subject on Physical Education (or Games and Sports) for Students with Special Education Needs, so not all physical educators received specific training in our subject of interest. In fact, the current ECTS system removed the specific qualification in physical education, so PE contents are included in an optional itinerary of 48 ECTS credits. In addition, some universities in the peninsular region offer some training about inclusion in PE as part of that optional itinerary, but not the two insular universities offering these studies.

The second key aspect for the higher SE improvement ratio in the insular PETs can be explained by the characteristics of the education curricula to be delivered. The curriculum is an important concept as it allows the adoption of teaching practice guidelines and facilitates the declaration of educational intentions [31]. With regard to the (mandatory) secondary school curricula (12 to 16 years), the peninsular region featured in our study includes several curricular contents about our topic in a block entitled Games and Sports, including respect for different capabilities and the practice of inclusive games and specific para-sports such as boccia, goalball, para-badminton, or sitting volleyball [32]. However, the curriculum in the insular region does not include any content about IPE or para-sports, and there is very limited attention paid to the promotion of respect and acceptance of disability and social inclusion of students [33]. At the primary school level (6 to 12 years, a six-year pathway), the curriculum of the peninsular region also includes some content about our topic in the block entitled Games and Sport Activities, specifically in the third (adapted games and sports such as goalball or boccia), fourth (adapted and inclusive games), and fifth (respect to the differences and cooperative strategies) courses [34]. The curriculum of the insular region at this stage, again, does not include specific contents, with an isolated reference in respect to the differences in evaluation criteria for students [35]. As a consequence, the lack of specific content about IPE and/or para-sports in the educative curricula of the insular region might lead to a mis-qualification on this topic, explaining their lower SE scores prior to the intervention and their higher improvements ratios in all the SE subscales (i.e., intellectual, physical, and visual impairments). In this scenario, it is plausible to think that pre-service PETs from the insular region are more likely to be taught universal knowledge than more specific skills and strategies to accommodate students with special education needs [12].

The third factor underlying the uneven SE scores between regions could be related to geographical and demographic reasons. As of 2019, the Valencian Community is the fourth most populous region in Spain (4.98 million, $10.59 \%$ of the Spanish population), while the Canary Islands is the eighth (2.21 million, $4.51 \%$ of the Spanish population), with a population density of 212.79 and 293.89 people $/ \mathrm{km}^{2}$, respectively [36]. Although the population density in the Canary Islands is higher, the geographic discontinuity of the insular region, with seven islands, may cause some problems for sustainable education development [37]. In many cases, although teachers identify their training needs, the possibilities to do so are often more limited in an insular than in a peninsular region, especially due to a lack of education facilities, lack of specific training disciplines or lack of actualized choices (i.e., inclusive education) $[16,38]$. When this happens, teachers are required to move out of their homes [39], facing important financial and time costs and reducing training opportunities and the ability to keep up to date. This phenomenon is supported by recent statistics indicating that the Canary Islands present one of the lowest percentages of the population between 25 and 64 years with a university education (29.6\%) compared to the national average (36.7\%) [40]. If we transfer this calculation to the education field, the Canary Islands have a ratio of 8.47 teachers for every 100 students, 
while this ratio is 9.06 in the rest of the country. This data is in line with the Spanish situation regarding teaching resources when compared with other countries in the OECD, with lower teacher/student ratios

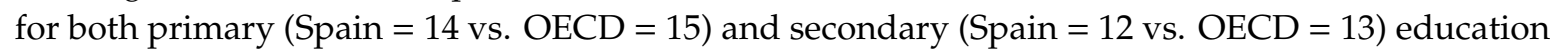
levels. In consequence, educators' workload is usually increased, constraining their available time or interest to increase their lifelong training.

Some limitations should be noted. First, the instructors involved in delivering the training program in the peninsular and the insular regions were not the same, which could constrain the internal validity of the study. However, this bias was controlled by providing a pre-intervention training by the principal investigator to achieve consistency among instructors. Second, the para-athletes involved in direct contact in the last session of the program were not the same, but guidelines for their participation were standardized across the courses. Third, the population density of the two main islands in the insular region (Gran Canaria and Tenerife) constrained the course locations to three of the seven islands in this study. The situation was similar in the peninsular region, with less involvement among professors from the inland areas of the region (i.e., longer traveling distance required to attend to the course). Fourth, although a previous study demonstrated that the program does not vary based on the education setting (i.e., primary or secondary schools) [8], it was not possible to report this variable here as it was not considered in the insular region.

Some practical applications and prospects have also been considered. The evidence provided in this study could be used by Spanish education stakeholders from other regions to implement life-long training opportunities about inclusion for in-service physical educators. In addition, the development of online materials may help involve educators from those areas that are far from where the courses took place. However, the authors of this study emphasize that education for sustainable development requires interactive, learner-centered, and action-oriented pedagogies and, therefore, contact with para-athletes must be guaranteed as part of the training. Finally, follow-up studies are required to test the long-term efficiency of this intervention, which includes training strategies such as simulation, information, curriculum intervention, and direct contact with para-athletes.

\section{Conclusions}

A face-to-face program consisting of six three-hour sessions is an effective way to increase in-service physical educators' self-efficacy in including students with intellectual, physical or visual disabilities in their PE classes, in courses delivered in both a peninsular and an insular region in Spain. The self-efficacy scores of the physical educators might be constrained by the content regarding inclusion in their pre-service training, the education policies of the region in which the teaching takes place or the geographical characteristics of their workplace. In consequence, those educators from the insular region increased their self-efficacy scores to a higher extent.

Supplementary Materials: The following are available online at http://www.mdpi.com/2071-1050/11/20/5824/s1, Incluye-T guide for PETs, adapted to the Canary Islands region.

Author Contributions: Conceptualization, R.R.; methodology, R.R., A.S., R.M., and A.R.; validation, R.R. and A.S.; investigation, R.R., A.S., R.M., and A.R.; resources, R.R. and A.S.; data curation, R.R.; writing-original draft preparation, R.R., A.S., R.M., and A.R.; writing-review and editing, R.R. and A.R.; visualization, R.R. and A.R.; supervision, R.R.; project administration, R.R.; funding acquisition, R.R. and A.S.

Funding: This research was funded by the Spanish Paralympic Committee, Trinidad Alfonso Foundation (Valencian Community), and DISA Foundation (Canary Islands).

Acknowledgments: The authors would like to thank the staff from the regional offices for education affairs and all the para-athletes attending the last session of the courses delivered in both regions for their support.

Conflicts of Interest: The authors declare no conflict of interest. 


\section{References}

1. UNESCO. The Right to Education: Towards Education for All Through Life; World Education Report; UNESCO Publishing: Paris, France, 2000.

2. Wilhelmsen, T.; Sørensen, M. Inclusion of children with disabilities in physical education: A systematic review of literature from 2009 to 2015. Adapt. Phys. Act. Q. 2017, 34, 311-337. [CrossRef] [PubMed]

3. Maher, A. The inclusion of pupils with special educational needs. Sport Sci. Rev. 2010, 19, 263-283. [CrossRef]

4. OECD. Teachers and School Leaders as Lifelong Learners: TALIS 2018 Results (Volume 1). 2019. Available online: https:/www.oecd-ilibrary.org/education/talis-2018-results-volume-i_1d0bc92a-en (accessed on 24 June 2019).

5. UNESCO. Education for All Global Monitoring Report 2015: Education for All 2000-2015-Achievements and Challenges; UNESCO Publishing: Paris, France, 2015.

6. Beamer, J.A.; Yun, J. Physical educators' beliefs and self-reported behaviors towards including students with autism spectrum disorder. Adapt. Phys. Act. Q. 2014, 31, 362-376. [CrossRef] [PubMed]

7. Hodge, S.R.; Elliott, G. Physical education majors' judgments about inclusion and teaching students with disabilities. J. Educ. Train. Stud. 2013, 1, 151-157. [CrossRef]

8. Reina, R.; Healy, S.; Roldan, A.; Hemmelmayr, I.; Klavina, A. Incluye-T: A professional development program to increase the self-efficacy of physical educators towards inclusion. Phys. Educ. Sport Peda 2019, 24, 319-331. [CrossRef]

9. Rosenzweig, K. Are Today's General Education Teachers Prepared to Meet the Needs of Their Inclusive Students? In Northeastern Educational Research Association (NERA) Annual Conference Proceedings; University of Connecticut: Rocky Hill, CT, USA, 2009; Available online: https://opencommons.uconn.edu/nera_2009/10/ (accessed on 24 June 2019).

10. Kane, T.J.; Taylor, E.S.; Tyler, J.H.; Wooten, A.L. Identifying effective classroom practices using student achievement data. J. Hum. Resour. 2011, 46, 587-613.

11. Cook, B.G.; Odom, S.L. Evidence-based practices and implementation science in special education. Except. Child. 2013, 79, 135-144. [CrossRef]

12. Flower, A.; McKenna, J.W.; Haring, C.D. Behavior and classroom management: Are teacher preparation programs really preparing our teachers? Prev. Sch. Fail. 2017, 61, 163-169. [CrossRef]

13. Verdis, A.; Kalogeropoulos, K.; Chalkias, C. Regional disparities in access to higher education in Greece. Res. Comp. Int. Educ. 2019, 14, 318-335. [CrossRef]

14. Butler, T.; Hamnett, C. The geography of education: Introduction. Urban Stud. 2007, 44, 1161-1174. [CrossRef]

15. MECD, Ministerio de Educación, Cultura y Deporte. Ley Orgánica 8/2013, 9 de Diciembre, Para la Mejora de la Calidad Educativa (LOMCE). BOE Núm. 295. 2013. Available online: https://www.boe.es/buscar/pdf/ 2013/BOE-A-2013-12886-consolidado.pdf (accessed on 17 July 2019).

16. Kelly, A.; Azaola, M.C.; Schulz, J. Island voices: Choice, equity and opportunity in Jersey schools. Camb. J. Educ. 2019. [CrossRef]

17. Block, M.E.; Hutzler, Y.; Barak, S.; Klavina, A. Creation and validation of the self-efficacy instrument for physical education teacher education majors toward inclusion. Adapt. Phys. Act. Q. 2013, 30, $184-205$. [CrossRef]

18. Reina, R.; Hemmelmayr, I.; Sierra-Marroquín, B. Autoeficacia de profesores de educación física para la inclusión de alumnos con discapacidad y su relación con la formación y el contacto previo. Psychol. Soc. Educ. 2016, 8, 93-103. [CrossRef]

19. Nunnally, J.; Bernstein, L. Psychometric Theory; McGraw-Hill Higher, Inc.: New York, NY, USA, 1994.

20. Hopkins, W.; Marshall, S.; Batterham, A.; Hanin, J. Progressive statistics for studies in sports medicine and exercise science. Med. Sci. Sports Exerc. 2009, 41, 3-13. [CrossRef] [PubMed]

21. Pierce, C.A.; Block, R.A.; Aguinis, H. Cautionary note on reporting eta-squared values from multifactor ANOVA designs. Educ. Psychol. Meas. 2004, 64, 916-924. [CrossRef]

22. Cohen, J. Statistical Power Analysis for the Behavioral Sciences; Routledge Academic: New York, NY, USA, 1988.

23. Lindsay, S.; Edwards, A. A systematic review of disability awareness interventions for children and youth. Disabil. Rehabil. 2013, 35, 623-646. [CrossRef]

24. Colwell, C.M.; Thompson, L.K.; Berke, M.K. Disability simulations and information: Techniques for modifying the attitudes of elementary school music students. J. Music Ther. 2001, 38, 321-341. [CrossRef] 
25. Goddard, L.; Jordan, L. Changing attitudes about persons with disabilities: Effects of a simulation. J. Neurosci. Nurs. 1998, 30, 307-314. [CrossRef]

26. Block, M.E.; Kwon, E.H.; Healy, S. Preparing future physical educators for inclusion: Changing the physical education teacher training program. J. Braz. Soc. Adapt. Mot. Activ. 2016, 17, 9-12.

27. Allport, G.W. The Nature of Prejudice; Addison-Wesley: Boston, MA, USA, 1954.

28. McKay, C. The value of contact: Unpacking Allport's Contact Theory to support inclusive education. Palaestra 2018, 32, 21-25.

29. McKay, C.; Haegele, J.; Block, M. Lessons learned from Paralympic School Day: Reflections from the students. Eur. Phys. Educ. Rev. 2018, 25, 745-760. [CrossRef]

30. Del Villar, F. Propuesta de Título de Grado en Ciencias de la Actividad Física y del Deporte. In Programa de Convergencia Europea; ANECA: Madrid, Spain, 2004.

31. Fernández-Cruz, M. El desarrollo docente en los escenarios del currículum y la organización. Profr Rev. Curr. Form. Profr. 2011, 8, 1-20.

32. Decreto 51/2018, de 27 de Abril, del Consell, Por el Que se Modifica el Decreto 87/2015, por el que Establece el Currículo y Desarrolla la Ordenación General de la Educación Secundaria Obligatoria y del Bachillerato en la Comunitat Valenciana. DOGV Núm 7544. Available online: http://www.dogv.gva.es/datos/2018/04/30/ pdf/2018_4258.pdf (accessed on 3 September 2019).

33. Decreto 83/2016, de 4 de Julio, Por el Que se Establece el Currículo de la Educación Secundaria Obligatoria y el Bachillerato en la Comunidad Autónoma de Canarias. BOC Núm 136. Available online: http: //www.gobiernodecanarias.org/boc/2016/136/001.html (accessed on 3 September 2019).

34. Decreto 108/2014, de 4 de Julio, del Consell, Por el Que Establece el Currículo y Desarrolla la Ordenación General de la Educación Primaria en la Comunitat Valenciana. DOGV Núm 7311. Available online: http://www.dogv.gva.es/datos/2014/07/07/pdf/2014_6347.pdf (accessed on 3 September 2019).

35. Decreto 89/2014, de 1 de Agosto, Por el Que se Establece la Ordenación y el Currículo de la Educación Primaria en la Comunidad Autónoma de Canarias. BOC Núm 156. Available online: http://www.gobiernodecanarias. org/boc/2014/156/001.html (accessed on 3 September 2019).

36. Red Española de Información Sobre Educación (REDIE). Available online: https://www.educacionyfp.gob.es/ educacion/mc/redie-eurydice/sistemas-educativos/e-secundaria.html (accessed on 22 September 2019).

37. Douglas, H.C. Small island states and territories: Sustainable development issues and strategies-challenges for changing islands in a changing world. Sustain. Dev. 2006, 14, 75-80. [CrossRef]

38. Christofakis, M.; Mergos, G.; Papadaskalopoulos, A. Sustainable and balanced development of insular space: The case of Greece. Sustain. Dev. 2009, 17, 365-377. [CrossRef]

39. Kerr, J.Q.; Hess, D.J.; Smith, C.M.; Hadfield, M.G. Recognizing and reducing barriers to science and math education and STEM careers for native Hawaiians and Pacific Islanders. CBE_Life Sci. Educ. 2018, 17, mr1. [CrossRef]

40. CaixaBank Research. La Economía de la Comunidad Autónoma de Canarias: Diagnóstico Estratégico. 2017. Available online: https://www.caixabankresearch.com/publicaciones/comunidades-autonomas (accessed on 12 September 2019).

(C) 2019 by the authors. Licensee MDPI, Basel, Switzerland. This article is an open access article distributed under the terms and conditions of the Creative Commons Attribution (CC BY) license (http://creativecommons.org/licenses/by/4.0/). 